\title{
Reinforced Concrete Structure Composition Analysis after Electrochemical Chloride Extraction
}

\author{
Ning Xue*, Xingwang Liu, Hanbo Jia, Yingshuai Wu and Jingjun Ma* \\ College of Science and Technology, Agricultural University of Hebei, Huanghua, 061100, P.R. China \\ *E-mail: mjjwjpmartin@163.com ; xingangliu@yahoo.com
}

doi: $10.20964 / 2016.10 .10$

Received: 3 July 2016 / Accepted: 8 August 2016 / Published: 6 September 2016

\begin{abstract}
Corrosion of reinforcing steel bar is one of the major reasons for the deterioration of reinforced concrete structures. Chloride permeation from deicing salts, seawater or other environmental causes is the primary reason for the corrosion. Electrochemical Chloride Extraction (ECE) is a simple and lowcost technique whereby chlorides could be removed from contaminated concrete. However, side effect of the ECE process was commonly observed on the ordinary Portland cement. In this study, we used the ordinary Portland cement as a control group and investigated the ECE efficiency and side effect of the blended cement with different composition. Micro vickers hardness tester and mercury intrusion porosimetry were used for characterizing the microstructural properties of the mortar samples. A higher chloride removal efficiency was observed on the ordinary Portland cement made mortar compared with that of the blend cement made mortar. The microhardness difference before and after ECE process of the mortar sample made by blend cement is much higher than that of the mortar sample made by the ordinary Portland cement.
\end{abstract}

Keywords: Electrochemical chloride extraction; Reinforced concrete; Cement; Microhardness

\section{$\underline{\text { FULL TEXT }}$}

(C) 2016 The Authors. Published by ESG (www.electrochemsci.org). This article is an open access article distributed under the terms and conditions of the Creative Commons Attribution license (http://creativecommons.org/licenses/by/4.0/). 